\title{
The mitral valve prolapse frequency in healthy females with generalized joint hypermobility: A case-control study
}

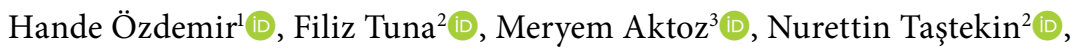 \\ Derya Demirbağ Kabayel² \\ ${ }^{1}$ Department of Physical Therapy and Rehabilitation, Uzunköprü State Hospital, Edirne, Turkey \\ ${ }^{2}$ Department of Physical Therapy and Rehabilitation, Trakya University Faculty of Medicine, Edirne, Turkey \\ ${ }^{3}$ Department of Cardiology, Trakya University Faculty of Medicine, Edirne, Turkey
}

\begin{abstract}
Objectives: The aim of this study was to investigate the frequency of mitral valve prolapse between healthy females with generalized joint hypermobility and healthy controls.

Patients and methods: This observational, cross-sectional, controlled study included female individuals with generalized joint hypermobility $(n=39$, mean age: $20.5 \pm 1.1$ years; range, 19 to 23 years) and healthy controls ( $n=42$, mean age: $20.6 \pm 1.2$ years; range, 18 to 23 years) between July 2017 and November 2017. The generalized joint hypermobility consisted of women with a Beighton score of $\geq 4$, while the control group consisted of women with a Beighton score of $\leq 3$. Echocardiography was performed to all participants. Mitral valve prolapse was defined as having single or bileaflet prolapse of at least $2 \mathrm{~mm}$ beyond the long-axis annular plane with or without mitral leaflet thickening.

Results: No significant difference was found in the age, height, body weight, and body mass index between the groups ( $p>0.05$ ). The median Beighton score was 5 in the generalized joint hypermobility group and 2 in the control group. No mitral valve prolapse was detected in those with generalized joint hypermobility, while non-classical mitral valve prolapse was observed in one participant in the control group, indicating no statistically significant difference between the two groups $(p>0.05)$.

Conclusion: Our study results suggest that the frequency of mitral valve prolapse is comparable between the women with generalized joint hypermobility and healthy controls. Based on these results, routine assessment of mitral valve prolapse is not recommended in this population. Keywords: Echocardiography, heart valve disease, joint laxity, women.
\end{abstract}

Joint hypermobility based on ligamentous laxity is the joint range of motion of certain synovial joints above normal limits. ${ }^{1}$ The presence of joint hypermobility in multiple joints of an individual refers to generalized joint hypermobility (GJH) and is usually evaluated with Beighton score. ${ }^{2}$ Generalized joint hypermobility can be a feature of connective tissue diseases such as Marfan syndrome, Ehlers-Danlos syndrome (EDS) and osteogenesis imperfecta, and joint hypermobility syndrome or, a feature with a hereditary transition in healthy individuals. Although these three conditions have different clinical features, they are often mistakenly considered the same. ${ }^{3}$

Received: April 23, 2020 Accepted: October 18, 2020 Published online: January 21, 2021

Correspondence: Hande Özdemir, MD. Uzunköprü Devlet Hastanesi, Fizik Tedavi ve Rehabilitasyon Kliniği, 22300 Uzunköprü, Edirne, Türkiye. Tel: +90 284 - 5131514 e-mail: handeozdemirmd@gmail.com

Citation:

Özdemir H, Tuna F, Aktoz M, Taştekin N, Demirbağ Kabayel D. The mitral valve prolapse frequency in healthy females with generalized joint hypermobility: A case-control study. Arch Rheumatol 2021;36(3):335-340.

()2021 Turkish League Against Rheumatism. All rights reserved.

This is an open access article under the terms of the Creative Commons Attribution-NonCommercial License, which permits use, distribution and reproduction in any medium, provided the original work is properly cited and is not used for commercial purposes (http://creativecommons.org/licenses/by-nc/4.0/). 
Generalized joint hypermobility is quite common in the general population, particularly in children and young females. ${ }^{4,5}$ The prevalence of $\mathrm{GJH}$ in individuals with an age range of 17 to 26 years has been reported to be 42 to $51 \%$ in women and 22 to $27 \%$ in men. ${ }^{5,6}$ It is often congenital and possibly an inherited condition. ${ }^{3}$

Although most of patients with GJH are asymptomatic, GJH can be associated with various musculoskeletal problems. ${ }^{4}$ In the study of Tuna, $51 \%$ of young female individuals with GJH were reported to be asymptomatic. On the other hand, individuals with GJH accompanied by musculoskeletal complaints such as arthralgia, back pain, and soft tissue problems are diagnosed with benign joint hypermobility syndrome (BJHS) based on the Brighton criteria. $^{7}$

Mitral valve prolapse (MVP) is a heart valve disease characterized by the bulging of one or both mitral valves into the left atrium and affects between 2 and 3\% of the general population. ${ }^{8}$ It is a disease of the young and is more common in women than men. ${ }^{8}$ In addition, MVP can cause severe mitral insufficiency, bacterial endocarditis, congestive heart failure, and even sudden cardiac death. ${ }^{9}$

To date, case-control studies and meta-analyses have almost entirely been conducted in patients with MVP and symptomatic joint hypermobility such as BJHS, ${ }^{10-18}$ or connective tissue diseases such as EDS, Marfan syndrome. ${ }^{19,20}$ The MVP has been reported to be common among patients with joint hypermobility syndrome. ${ }^{10-12,21}$ Furthermore, the dilemma of MVP-associated GJH continued as a "casual coincidence, common link, or fundamental genetic disturbance". ${ }^{22}$ Recently, Tuna et al. ${ }^{23}$ reported that healthy women with GJH had different gene expressions (higher SLC39A13 and TNXB, and lower DSE, FKBP14, COL1A1, COL1A2, and COL5A1) than the non-hypermobile controls. In addition, GJH is a common feature in EDS types in which disorders of collagen primary structure and collagen processing have been already known. Considering the possibility that currently healthy females with GJH differ from nonhypermobile females, in the present study, we aimed to investigate the frequency of MVP between healthy females with GJH and healthy controls.

\section{PATIENTS AND METHODS}

This observational, cross-sectional, controlled study was conducted at Trakya University Faculty of Medicine between July 2017 and November 2017. Since GJH and MVP occur more frequently in women than in men, $5,6,8$ the current study included female participants only. The Beighton score evaluations were applied to the females for GJH assessment (Table 1). Women with a Beighton score of $\leq 3$ out of 9 were considered as the controls, and those with a Beighton score of $\geq 4$ out of 9 were considered as the GJH population. Finally, the study included female individuals with $\mathrm{GJH}(\mathrm{n}=39$, mean age: $20.5 \pm 1.1$ years; range, 19 to 23 years) and healthy controls $(n=42$, mean age: $20.6 \pm 1.2$ years; range, 18 to 23 years). Inclusion criteria were age of 18 to 35 years and female sex. Exclusion criteria were symptomatic GJH according to the Brighton criteria (Table 1), having musculoskeletal surgery within the past one year, having any disease of the locomotor system, and presence of genetic disorders. A written informed consent was obtained from each participant. The study protocol was approved by the Trakya University Faculty of Medicine Ethics Committee. The study was conducted in accordance with the principles of the Declaration of Helsinki.

Echocardiography was performed to all participants. Mitral valve prolapse was defined as having single or bileaflet prolapse of at least $2 \mathrm{~mm}$ beyond the long-axis annular plane with or without mitral leaflet thickening. Prolapse with thickening of the leaflets greater than $5 \mathrm{~mm}$ was defined as classic prolapse, whereas prolapse with lesser degrees of leaflet thickening was defined as non-classic prolapse. ${ }^{9}$

\section{Statistical analysis}

Statistical analysis was performed using the IBM SPSS version 20.0 software (IBM Corp., Armonk, NY, USA). Descriptive data were expressed in mean \pm standard deviation (SD), median (min-max) or number and frequency. 
Table 1. The Beighton score and the Brighton criteria ${ }^{2,7}$

Beighton score

- Passive dorsiflexion of the little finger $>90^{\circ}$ (one point for each hand)-two points

- Passive apposition of the thumb to the flexor aspect of the forearm (one point for each thumb)-two points

- Active hyperextension of the elbow $>10^{\circ}$ (one point for each elbow)-two points

- Active hyperextension of the knee $>10^{\circ}$ (one point for each knee)-two point

- Ability to place hands flat on the floor with knees fully extended-one point

Brighton criteria

Major criteria

- A Beighton score of $\geq 4 / 9$

- Arthralgia ( $\geq 3$ months) in $\geq 4$ joint

Minor criteria

- Beighton score of 1-3 (0-3 if age 50 years or older)

- Arthralgia ( $\geq 3$ months) in 1-3 joints or back pain ( $\geq 3$ months), spondylosis, spondylolysis/spondylolisthesis

- Dislocation/subluxation in $\geq 1$ joint, or in 1 joint on $\geq 1$ occasion

- Soft tissue rheumatism, $\geq 3$ lesions (e.g., epicondylitis, tensosynovitis, bursitis)

- Marfanoid habitus (tall, slim, span:height ratio $>1.03$, upper: lower segment $<0.89$, arachnodactyly [positive Steinberg/wrist sign])

- Abnormal skin: striae, hyperextensibility, thin skin, papyraceous scarring

- Eye signs: drooping eyelids or myopia or antimongoloid slant

- Varicose veins or hernia or uterine/rectal prolapse

Diagnosis of BJHS requires the presence of two major criteria, or one major and two minor criteria, or four minor criteria, or 2 minor criteria and unequivocally one or more first-degree affected relative(s). The disorder is excluded in those patients with Marfan and Ehler-Danlos (other than hypermobility type) syndrome.

A single-sample Kolmogorov-Smirnov test was used to analyze whether the data were normally distributed. The Student t-test and the Chi-square test were used to examine the differences in the demographic characteristics and the frequency of MVP between the control and GJH groups, respectively. A $p$ value of $<0.05$ was considered statistically significant.

\section{RESULTS}

There was no significant difference between the two groups in terms of age ( $p>0.05)$, height, body weight, and body mass index ( $>0.05$ for all) (Table 2).

The median Beighton score was 5 (range, 5 to 9) in the GJH group and 2

Table 2. Demographic and echocardiographic findings of the GJH group and the control group

\begin{tabular}{|c|c|c|c|c|c|c|}
\hline \multirow[b]{2}{*}{ Findings } & \multicolumn{3}{|c|}{ GJH group $(n=39)$} & \multicolumn{3}{|c|}{ Control group $(\mathrm{n}=42)$} \\
\hline & $\mathrm{n}$ & Mean \pm SD & Range & $\mathrm{n}$ & Mean \pm SD & Range \\
\hline Mean age (year) & & $20.5 \pm 1.1$ & $19-23$ & & $20.6 \pm 1.2$ & $18-23$ \\
\hline \multicolumn{7}{|l|}{ Beighton score } \\
\hline $0-3$ & 0 & & & 42 & & \\
\hline 4 & 0 & & & 0 & & \\
\hline 5 & 26 & & & 0 & & \\
\hline 6 & 7 & & & 0 & & \\
\hline 7 & 4 & & & 0 & & \\
\hline 8 & 1 & & & 0 & & \\
\hline 9 & 1 & & & 0 & & \\
\hline Median Beighton score & 5 & & & 2 & & \\
\hline Mitral valve prolapse & 0 & & & 1 & & \\
\hline
\end{tabular}


(range, 0 to 3 ) in the control group (Table 2). According to the echocardiographic examination, no MVP was detected in the GJH group, whereas non-classical MVP was observed in one participant in the control group, indicating no statistically significant difference between the two groups $(p>0.05)$. The participant with MVP had a Beighton score of 2 and had a $3-\mathrm{mm}$ prolapse in the anterior mitral leaflet with $4-\mathrm{mm}$ thickness of the leaflet. In this patient, no mitral insufficiency was detected and the left atrial dimension, left ventricular end-diastolic and endsystolic diameters, and ejection fraction were found to be normal.

\section{DISCUSSION}

In the present study, we investigated whether the frequency of MVP differed between healthy females with GJH and healthy controls. The study results showed that there was no significant relationship between MVP and GJH among the currently healthy females. In addition, none of the participants with GJH had echocardiographic findings consistent with MVP.

Mitral valve prolapse may occur due to histological abnormalities in the valvular tissue, ventricular-mitral disproportion, or various connective disorders. Myxomatous degeneration is the most common histological abnormality causing MVP. ${ }^{24}$ Earlier studies in the 1980s showed the presence of collagen abnormalities in the myxomatous mitral valves. ${ }^{25}$ Another study suggested that these abnormalities were similar to those found in skin biopsies in patients with joint hypermobility syndrome. ${ }^{10}$ Later on, the relationship between joint hypermobility syndrome and MVP became a subject of curiosity for many researchers, and several studies were conducted to examine the frequency of MVP in individuals with joint hypermobility syndrome or vice versa. Thanks to the development of modern echocardiography techniques and new echocardiography criteria, there has been an ongoing need for studies using new criteria since 1990s. However, none of these studies included asymptomatic participants with joint hypermobility, as in our study.

Although nearly half of individuals with GJH are asymptomatic and the other half is symptomatic, an individual with GJH should be questioned in terms of the presence of symptoms to achieve methodological precision. ${ }^{5}$ Due to the research gap regarding the correlation between MVP and asymptomatic individuals with GJH, which is the focus of the current study, we discuss the results of previous studies on MVP in joint hypermobility syndrome or joint hypermobility syndrome in MVP, already known in the current literature.

Conflicting results regarding the prevalence of MVP have been reported in studies of different ethnic groups with joint hypermobility syndrome. Handler et al. ${ }^{10}$ reported that women with joint hypermobility syndrome were at least three times more prone to MVP than the normal adult population. In the Mohammed's study, ${ }^{11}$ the prevalence of MVP was $28.9 \%$ in patients with joint hypermobility syndrome and $6.7 \%$ in the control group. In another study, Kozanoglu et al., ${ }^{12}$ examined whether joint hypermobility syndrome increased the risk of MVP in patients with fibromyalgia and concluded that MVP was seen approximately nine times more often in women with fibromyalgia having joint hypermobility syndrome than those without joint hypermobility, while some other studies suggested that joint hypermobility syndrome was not associated with an increased frequency of MVP. ${ }^{13-15}$ On the other hand, Ondrasik et al. ${ }^{16}$ and Pitcher and Grahame ${ }^{17}$ found a significantly higher prevalence of joint hypermobility syndrome (52\% and 33\%, respectively) in MVP patients. Similarly, Yazici et al. ${ }^{18}$ reported that the incidence of joint hypermobility syndrome was $45 \%$ in patients with MVP, whereas it was $12 \%$ in the controls. In addition, a correlation between the echocardiographic features of the mitral valve and elastic properties of the aortic wall and the severity of joint hypermobility syndrome was found. However, in the study by Marks et al., ${ }^{26}$ none of 37 adults with MVP had a Beighton score above 3. Of note, in the aforementioned studies, different diagnostic criteria such as Beighton score, ${ }^{10,11,16,17}$ Carter-Wilkinson criteria, ${ }^{15}$ or Brighton criteria ${ }^{12-14,18}$ were used in the diagnosis of BJHS. The conceptual confusion between the terms GJH and BJHS frequently occurs in studies of joint hypermobility. In the present study, we evaluated the frequency of MVP using the current echocardiographic criteria in asymptomatic 
individuals with GJH as assessed by the Beighton score. To the best of our knowledge, this study is the first to report the frequency of MVP in currently healthy individuals with GJH.

Nonetheless, there are some limitations to this study. Relatively small sample size and the inclusion of only female participants are the main limitations. Therefore, the results cannot be generalized to the entire population and further large-scale, prospective studies are needed to confirm these findings.

In conclusion, our study results suggest that the frequency of MVP is comparable between the women with GJH and healthy controls. This finding again highlights the difference between joint hypermobility syndrome and healthy individuals with GJH. In the presence of highly prevalent GJH in the society, assessment of the presence of MVP may cause anxiety. We also consider that the routine echocardiographic evaluation in healthy individuals with GJH may cause unnecessary financial burden on the healthcare system.

\section{Declaration of conflicting interests}

The authors declared no conflicts of interest with respect to the authorship and/or publication of this article.

\section{Funding}

This research was supported by the Scientific Research Committee of the Trakya University Scientific Research Projects Unit.

\section{REFERENCES}

1. Beighton P, Solomon L, Soskolne CL. Articular mobility in an African population. Ann Rheum Dis 1973;32:413-8.

2. Beighton PH, Grahame R, Bird HA. Hypermobility of joints. 4th ed. London: Springer Science \& Business Media; 2011.

3. Castori M, Tinkle B, Levy H, Grahame R, Malfait F, Hakim A. A framework for the classification of joint hypermobility and related conditions. Am J Med Genet C Semin Med Genet 2017;175:148-57.

4. Castori M, Hakim A. Contemporary approach to joint hypermobility and related disorders. Curr Opin Pediatr 2017;29:640-9.

5. Tuna F. Prevalence of joint hypermobility, hypermobility spectrum disorder and hypermobile Ehlers-Danlos syndrome in a university population: an observational study. The European Research Journal 2020;6:120-9.

6. Russek LN, Errico DM. Prevalence, injury rate and, symptom frequency in generalized joint laxity and joint hypermobility syndrome in a "healthy" college population. Clin Rheumatol 2016;35:1029-39.

7. Grahame R, Bird HA, Child A. The revised (Brighton 1998) criteria for the diagnosis of benign joint hypermobility syndrome (BJHS). J Rheumatol 2000;27:1777-9.

8. McLachlan J, Reddy PC, Ratts TE. Mitral valve prolapse. A common cardiac diagnosis in women. J La State Med Soc 1998;150:92-6.

9. Delling FN, Vasan RS. Epidemiology and pathophysiology of mitral valve prolapse: new insights into disease progression, genetics, and molecular basis. Circulation 2014;129:2158-70.

10. Handler CE, Child A, Light ND, Dorrance DE. Mitral valve prolapse, aortic compliance, and skin collagen in joint hypermobility syndrome. Br Heart $\mathrm{J}$ 1985;54:501-8.

11. Mohammed TJ. Mitral Valve Prolapse In Patients With Benign Joint Hypermobility Syndrome (BJHS). AL-Kindy College Medical Journal 2017;13:8-10.

12. Kozanoglu E, Benlidayi IC, Akilli RE, Tasal A. Is there any link between joint hypermobility and mitral valve prolapse in patients with fibromyalgia syndrome? Clin Rheumatol 2016;35:1041-4.

13. Patel A, Schwartz M, Cohen L, Shindler D, Moreyra A, Schlesinger N. Mitral valve prolapse in patients with joint hypermobility syndrome. Arthritis Rheum 2015;67:385-6.

14. Mishra MB, Ryan P, Atkinson P, Taylor H, Bell J, Calver D, et al. Extra-articular features of benign joint hypermobility syndrome. $\mathrm{Br} \mathrm{J}$ Rheumatol 1996;35:861-6.

15. Jessee EF, Owen DS Jr, Sagar KB. The benign hypermobile joint syndrome. Arthritis Rheum 1980;23:1053-6.

16. Ondrasík M, Rybár I, Rus V, Bosák V. Joint hypermobility in primary mitral valve prolapse patients. Clin Rheumatol 1988;7:69-73.

17. Pitcher D, Grahame R. Mitral valve prolapse and joint hypermobility: evidence for a systemic connective tissue abnormality? Ann Rheum Dis 1982;41:352-4.

18. Yazici M, Ataoglu S, Makarc S, Sarı I, Erbilen $\mathrm{E}$, Albayrak S, et al. The Relationship Between Echocardiographic Features of Mitral Valve and Elastic Proporties of Aortic Wall and Beighton Hypermobility Score in Patients With Mitral Valve Prolapse. Jpn Heart J 2004;45:447-60.

19. Atzinger CL, Meyer RA, Khoury PR, Gao Z, Tinkle BT. Cross-sectional and longitudinal assessment of aortic root dilation and valvular anomalies in hypermobile and classic Ehlers-Danlos syndrome. J Pediatr 2011;158:826-30.e1. 
20. Rybczynski M, Mir TS, Sheikhzadeh S, Bernhardt AM, Schad C, Treede H, et al. Frequency and age-related course of mitral valve dysfunction in the Marfan syndrome. Am J Cardiol 2010;106:1048-53.

21. Grahame R, Edwards JC, Pitcher D, Gabell A, Harvey W. A clinical and echocardiographic study of patients with the hypermobility syndrome. Ann Rheum Dis 1981;40:541-6.

22. Malcolm AD. Mitral valve prolapse associated with other disorders. Casual coincidence, common link, or fundamental genetic disturbance? Br Heart J 1985;53:353-62.
23. Tuna F, Doğanlar ZB, Özdemir H, Demirbag Kabayel D, Doğanlar O. Ehlers-Danlos syndrome-related genes and serum strontium, zinc, and lithium levels in generalized joint hypermobility: a case-control study. Connect Tissue Res 2019:1-11.

24. Hayek E, Gring CN, Griffin BP. Mitral valve prolapse. Lancet 2005;365:507-18.

25. Cole WG, Chan D, Hickey AJ, Wilcken DE. Collagen composition of normal and myxomatous human mitral heart valves. Biochem J 1984;219:451-60.

26. Marks JS, Sharp J, Brear SG, Edwards JD. Normal joint mobility in mitral valve prolapse. Ann Rheum Dis 1983;42:54-5. 